\title{
Foreign Language Elementary Education of Infant Based on Multielement Analysis
}

\author{
Xiaokun Liu, a, Jian Zhou, ${ }^{2, b^{*}}$ and Ning $\mathrm{Cai}^{2, \mathrm{c}}$ \\ ${ }^{1}$ School of Foreign Languages, Northwest University for Nationalities, Lanzhou, China \\ ${ }^{2}$ School of Economics, Northwest University for Nationalities, Lanzhou, China \\ alxk0523@163.com, 'bhoujianfrank@126.com, ccaining91@tsinghua.org.cn \\ *The corresponding author
}

Keywords: Elementary education; Foreign education; Multielement analysis; Impact element

\begin{abstract}
This note discusses the Multielement problem of foreign language elementary education of infant. It is shown that almost the most guardians of a child did not really aware of the importance of foreign language elementary education methods in the process of children to grow up. In order to overcome the shortcomings of the upon, combined with a variety of external and internal factors which called Multielement Analysis is proposed. Theoretical analysis and experimental results testify that Multielement Analysis can effectively improve and deal with the problem of FLEE of infant.
\end{abstract}

\section{Introduction}

English has become a general open Chinese school and the longest course program [1]. In addition to more than two hundred million students and adults, even young children in learning foreign language. In most cases, who will select the English for the first foreign language [1,2]. Essentially speaking, the understanding of the nature of foreign language education is a reflect Foreign languages education. Any teaching behavior is always affected by some kind of education idea dominate. In this concept system, the core is the nature of foreign language education view and mindset, which leads the global and decided the development direction of the future foreign education. What about the nature of the foreign language education and how to locate the foreign language education during our life are our common focus today.

Generally, most English teachers only focus the language communication function, nevertheless who ignored the language of the cognitive, social culture and the nature of communication [3]. Language is a people know the world, to interpret the meaning of the world system and value system. Language is not only the tool of thinking, but also can let a person's thinking is active come, developed, let a person become more intelligent, more wisdom. People discover the language when they created the new world, created the humanity history. As a result, only understand Language education from the perspective of the significance of tool is a very narrow concept. To understand the nature of the language, the nature of language education is clear. Foreign language education only value how to control approaches will lead to ignore the students basic quality, especially humanistic quality and the cultivation of thinking ability. It is very necessarily to improve and enhance the awareness of Chinese children for to make a good foundation for Chinese students to study and clear the nature of English language [4].

\section{Multielement Analysis Model}

The key idea of our approach is that analysis of multiple factors on foreign language education in different level influence [4, 5]. There are many different foreign language education in China from native country. In this paper, we try to through the following several aspects to elaborate the importance of foreign language education in China. First of all, we need more and more attention of English basis education with the unceasing change of China's internationalization [5]. Apparently, early children education is paramount. English as an international communication official language 
which already by default as the first foreign language. China's parents will set the early enlightenment education for their children before in primary school. Thus, they will have a basis foundation than others. Of course, I believe that early foreign language training will lay a solid foundation of the habit of learning a foreign language in the future. Furthermore, English education is the biggest different from traditional academic education such as, Chinese, Mathematical etc. Which pay more attention to the expression of thinking logic and oral speaking.

According to the upon views, we can make a conclusion that English education play an important role in children comprehensive quality in the future. It's my conviction that only by doing so will we create a rosy education circumstance and future. Finally, how to value the foreign enlightenment education of children in a country like China has become the focus of the international education researcher. Some European and American scholars put forward that we have to fact up to the difficult of English education for non-native countries [6]. This allows us to better to find a way to crack. In the mean time, the government policies of value degree of foreign education have closely related to the success of foreign language education in the non- native countries.

We through the software of Supass to have a sample survey of the social. The experimental results show that there are five mainly reasons [7] have determines the success of foreign language education in China. They are respectively that the government education policies, the family economic, the background of family education [8], the learning atmosphere and the surrounding views. Dispersion from the collected data as follows:

$$
\begin{aligned}
& x_{i}=\frac{g(x) / \beta_{a}}{f(x) / \beta_{b}}+[f(x)+g(x)] / \beta_{l} \\
& \Delta x=|f(x)-g(x)|^{2} \\
& \Delta y=\left|\beta_{a}-\beta_{b}\right|^{2}
\end{aligned}
$$

Table 1 Multielement Accounted

\begin{tabular}{|l|l|l|l|l|l|}
\hline Factors & $\begin{array}{l}\text { The } \\
\text { Government } \\
\text { Education } \\
\text { Policies }\end{array}$ & $\begin{array}{l}\text { The Family } \\
\text { Economic }\end{array}$ & $\begin{array}{l}\text { The } \\
\text { Background } \\
\text { of Family } \\
\text { Education }\end{array}$ & $\begin{array}{l}\text { The } \\
\text { Learning } \\
\text { Atmosphere }\end{array}$ & $\begin{array}{l}\text { The } \\
\text { Surrounding } \\
\text { Views }\end{array}$ \\
\hline Accounted & $21 \%$ & $38 \%$ & $17 \%$ & $15 \%$ & $9 \%$ \\
\hline
\end{tabular}

Evidently, there are many uncollected data in this complex social [9]. We can through the software of Matlab to estimate the deviation from the real data. Firstly, we can set a hypothesis cure to distinguish the other cures. We model a virtual Multielement accounted [10] in which from many different factors and sources. We also define the average evaluate data that can be used to compare the productivity of different sizes. Asymptotically our model agrees with the chart of Multiement accounted analysis system. For certain dynamical system with given parameters, it is considered that this system has multistable phenomenon when the final developed state is dependent on the selection of initial values. Multistability provides certain convenience for functional diversity of the nervous system, and the changes of initial values can alter final states of the system 


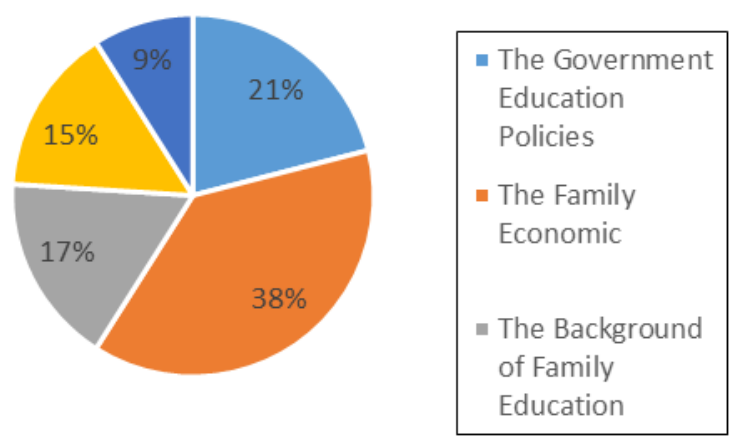

Figure 1. The Pie Chart of Multielement Accounted

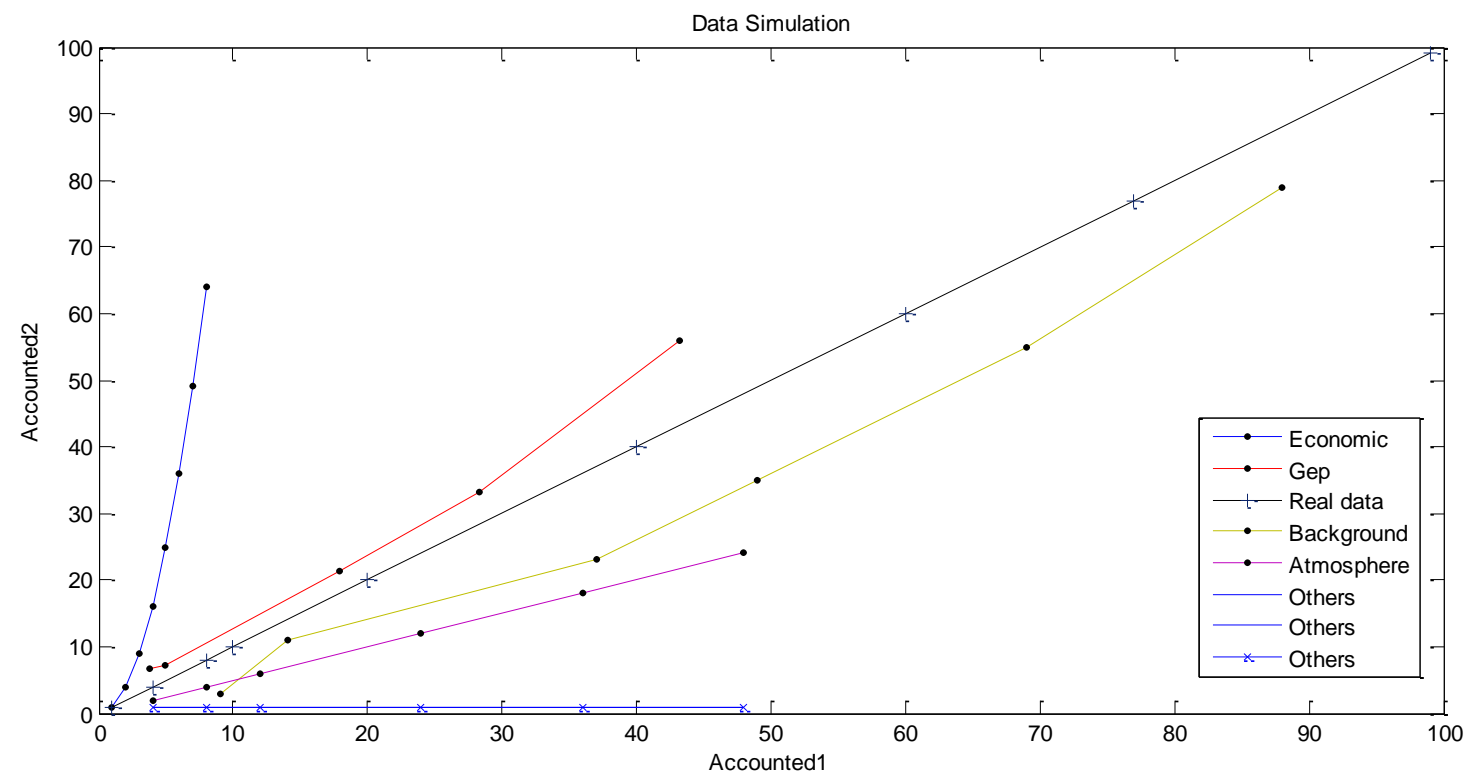

Figure 2. The Simulation of Real Data

\section{Conclusion}

In this paper we have presented a new approach to study the foreign language and foreign culture. We showed that we can capture the real properties of this sample agent-based model. Also a real data evaluation on an informetric data set was presented. And our approach also allows us to study and research the new concept of foreign language. Of course, there are still many issues worth deeper understanding and research. First of all, at least in theory, we need to redefine the concept of the English for Chinese children. Because of English is not mother tongue for Chinese, who will reject and accept the new language and new foreign culture in different degree. Moreover, foreign language education philosophy and Chinese traditional culture has many contradictions. Also, it is reasonable to perform similar analysis on different data sets.

We thank the reviewer for his relevant remarks and questions that allowed us to improve our paper. The Multielement analysis of different forms languages and culture are also left for future study.

\section{References}

[1] Altbach, P.G. (ed.) (2000). Comparative Higher Education: Knowledge, the University and Development. Boston: Boston College, Center for International Higher Education.

[2] Berg, C. and Teichler, U. (1988). 'Unveiling the hidden information in credentials: A proposal to Introduce a Supplement to Higher Education Diplomas', Higher Education in Europe 13(3), 
$13-24$.

[3] El-Khawas, E. (1994). Towards a global university: Status and outlook in the United States, Higher Education Management 6(1), 90-98.

[4] Lenn, M.P. (1999). 'The new technologies and borderless higher education: The quality Imperative', GATE News 3(2), 2-3, 6-8.

[5] Teichler, U. (2001). 'Bachelor-level programmers and degrees in Europe: Problems and Opportunities', Yliopistotieto 29(1), 8-15.

[6] Van der Wende, M. (2001). 'Internationalisation policies: About new trends and contrasting paradigms', Higher Education Policy 14(3), 249-259.

[7] Language Program Evaluation. Cambridge: Cambridge University Press, 1996Hughes,A.

[8] Understanding Second Language Acquisition. Oxford: Oxford University Press, 1985.

[9] Brown, G. \& G. Yule. Teaching the Spoken Language. Cambridge: Cambridge University Press, 1983.

[10]Testing for Language Teachers. Cambridge: Cambridge University Press, 1989. 